\title{
Implementation of Synchronous Telemedicine into Clinical Practice
}

\author{
Seema Khosla, MD, FCCP*
}

\section{KEYWORDS}

- Telemedicine $\bullet$ Telehealth $\bullet$ Synchronous $\bullet$ Center to home $\bullet$ Center to center $\bullet$ E-visit $\bullet$ Telemed

- Web-side manner

\section{KEY POINTS}

- How is a telemedicine program created? It begins with the decision-making process to determine whether synchronous telemedicine is appropriate for the clinician and the practice. Recent COVID19 changes are also discussed.

- Web presence is discussed, with a brief tutorial and high-impact tips to ensure an effective virtual visit.

- Various models of synchronous telemedicine to consider are explored, including center-to-center and center-to-home models.

- Technical considerations are reviewed. These considerations change rapidly, and telemedicine models adapt to an ever-changing market where the traditional office visit is being challenged by direct-to-consumer models.

- Population health: telemedicine and artificial intelligence-assisted algorithms may allow high-level overview of large patient populations to address sleep concerns as they relate to population health, occupational medicine, and transportation safety.

\section{IS TELEMEDICINE APPROPRIATE?}

When entertaining the idea of telemedicine, the first step is to assess whether this type of clinical visit is appropriate for the clinician and the clinical practice. The American Academy of Sleep Medicine (AASM) released a position statement on the use of sleep telemedicine in 2015 and this may help clinicians who are contemplating adding sleep telemedicine to their practice. Part of this assessment includes an honest evaluation of the clinician's comfort level both with pursuing something new and with technology itself. If the clinician is initially apprehensive about either one, it is often helpful to identify the specific issues that lead to the discomfort. For example, the clinician may be intimidated by the software or the hardware required to perform a synchronous telemedicine encounter. There are classes available in person or online that may ease this discomfort. The clinician should consider being coached or trained by someone with technical expertise. Perhaps the clinician is concerned about learning how to use an examination extender, such as an electronic stethoscope, and how to coordinate a physical examination with a telepresenter. Often there are educational resources provided by the vendor with a support team who can provide troubleshooting tips. The better the source of the discomfort can be identified, the more likely it is that a specific resolution exists. Is the

\footnotetext{
* ND Center for Sleep, 103B 4152 30th Avenue South Fargo, ND 58104, USA

E-mail address: skhosla@medbridgegroup.com
} 


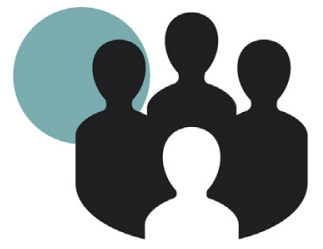

\section{Is Telemedicine Right for My Practice?}

Steps to Evaluate your Practice and your Patients

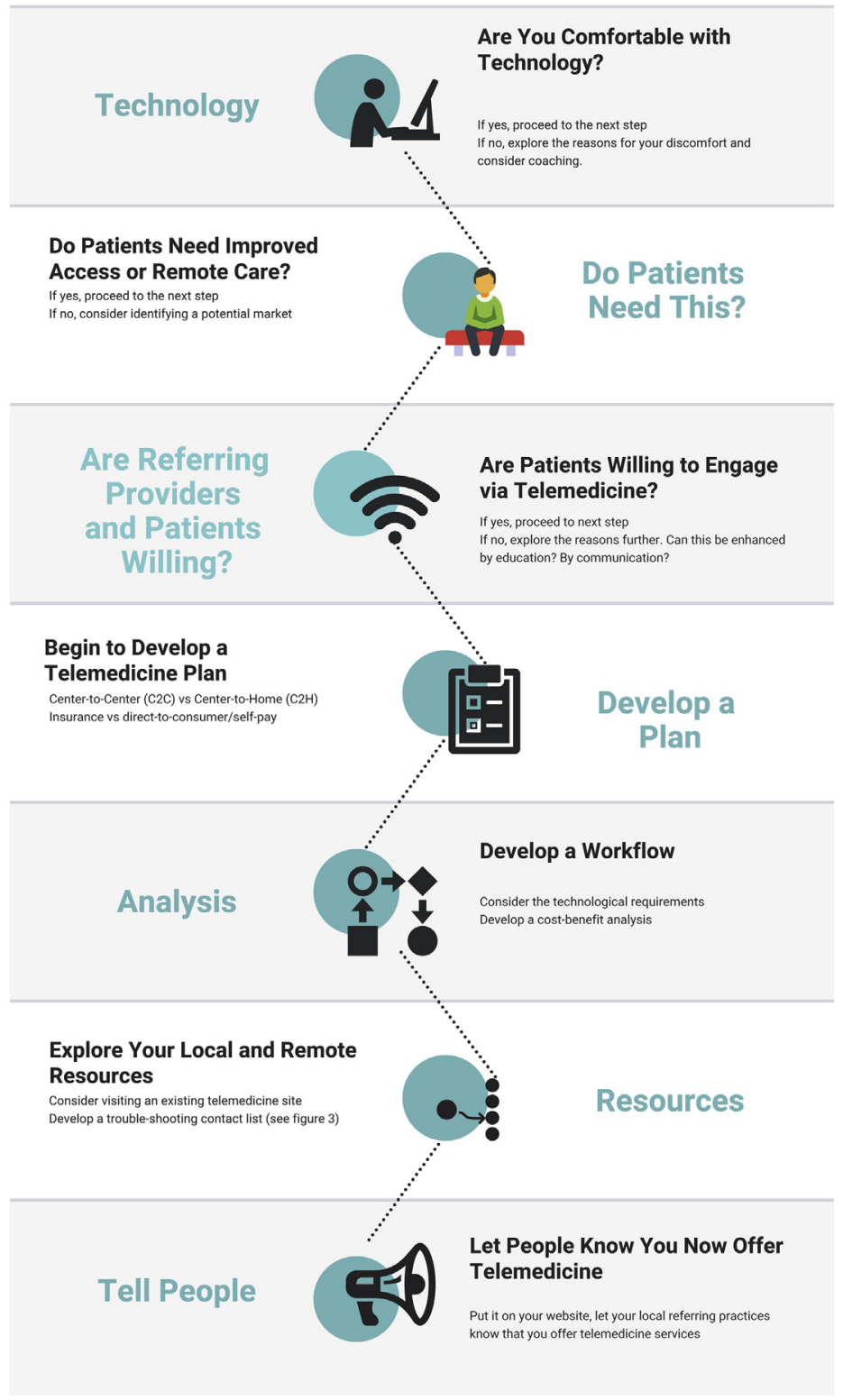

clinician uncomfortable with the idea of engaging with a patient remotely? There are classes and blogs available to teach about Web-side manner, such as this Webinar created by the National Consortium of Telehealth Resource Centers
Fig. 1. Algorithm to determine whether telemedicine is appropriate for a practice. (Courtesy of Dr Barry Fields, Atlanta, GA.) 
wait time? If the practice is currently overwhelmed with patients, then realistically there is no room for telemedicine patients. If the clinician is planning to transition current in-person patients to a telemedicine model, or if it has been determined that there is room in the clinic schedule, the next step is to assess the financial feasibility of a telemedicine practice.

This assessment involves an evaluation of both fixed costs (eg, start-up costs) and recurring costs (monthly costs). These costs depend on the level of sophistication of the system. If there is a geographic area that will be served, a determination needs to be made regarding telemedicine versus establishing a satellite clinic. A sample cost analysis worksheet is provided in Tables 1-3.

An important consideration is whether or not Medicare will reimburse for the remote visits. This consideration has recently changed with the COVID-19 pandemic. Because it is unclear whether current reimbursement guidelines will continue, this article includes some resources in case regulations revert back to the pre-COVID-19 situation. A helpful Web site is http://datawarehouse.hrsa.gov/ telehealthAdvisor/telehealthEligibility.aspx, which is based on the geographic location of the originating site (where the patient is). Once these fields have been populated and totals tabulated, a fiscal decision needs to be made regarding the feasibility of a telemedicine practice. If this makes financial sense for the practice, it is time to involve the clinical staff. The next step requires an objective look at the staff. Will they be champions or will they create barriers?
The staff's attitude toward telemedicine is critical. It is important to include them in the decisionmaking process. Telemedicine may initially seem like a way to streamline the clinic personnel but, in reality, the staff will have shifting responsibilities. A nurse will still be needed to room the patient and obtain vital signs. The scheduling staff will need to schedule telemedicine visits, unless a platform that will automate this process is used. The information technology (IT) staff will need to be involved in the telemedicine setup. They will need to ensure a Health Insurance Portability and Accountability Act (HIPAA)-compliant visit that satisfies the regulatory aspects of telemedicine. They are all already part of the team but now will likely work more closely on the telemedicine project. When staff members recognize the value of telemedicine, they often instinctively become telemedicine champions, especially when they see how patients benefit from this technology. It is vital to discuss the intent with the team and assess their willingness to embrace synchronous telemedicine. Listen to and acknowledge their concerns. A successful telemedicine program requires the support of the team. As Dr Singh points out earlier in this issue, synchronous telemedicine is an audiovisual, real-time visit between the patient and provider. As such, the staff need to treat this as any other clinic visit including previsit and postvisit duties. The aim of a telemedicine visit is to mirror the in-person visit as much as possible. If there is paperwork that needs to be completed before the visit, the same will need to be completed before a telemedicine visit. This requirement also applies to documentation after

\begin{tabular}{|c|c|c|c|c|}
\hline & Item & $\mathrm{C} 2 \mathrm{H}(\$)$ & $\mathrm{C} 2 \mathrm{C}(\$)$ & Satellite (\$) \\
\hline \multirow{11}{*}{ Monthly costs } & Clinic space & NA & - & - \\
\hline & Telemedicine technician/presenter & NA & - & $\mathrm{NA}$ \\
\hline & Other staff & NA & - & - \\
\hline & Practitioner travel & NA & NA & - \\
\hline & Staff travel & NA & NA & - \\
\hline & Software platform & - & - & $N \bar{A}$ \\
\hline & Public awareness/advertising & - & - & - \\
\hline & $\begin{array}{l}\text { Lost new in-person visits at } \\
\text { primary clinic }\end{array}$ & & & - \\
\hline & $\begin{array}{l}\text { Lost follow-up in-person visits at } \\
\text { primary clinic }\end{array}$ & & & \\
\hline & Lost HSATs from primary clinic & - & - & - \\
\hline & Lost PSGs from primary clinic & - & - & - \\
\hline$=$ & Other & - & - & - \\
\hline - & Total monthly costs & - & - & - \\
\hline
\end{tabular}

Abbreviation: NA, not applicable.

Courtesy of Dr Barry Fields, Atlanta, GA. 


\begin{tabular}{|cllll|}
\hline \multicolumn{2}{l}{$\begin{array}{l}\text { Table } 2 \\
\text { Cost analysis worksheet for single costs (start-up costs) }\end{array}$} & & \\
& Item & C2H Telemedicine (\$) & C2C Telemedicine (\$) & Satellite Clinic (\$) \\
\hline Single & Web camera & - & - & NA \\
costs & Telestethoscope & NA & - & NA \\
& $\begin{array}{c}\text { Oral examination } \\
\text { camera }\end{array}$ & NA & - & NA \\
& Other & - & - & - \\
\hline Total single costs & - & - & - \\
\hline
\end{tabular}

Courtesy of Dr Barry Fields, Atlanta, GA.

the visit and checkout procedures, including scheduling a test or arranging for Durable Medical Equipment (DME).

The next consideration is with respect to the potential patients. Will they be amenable to a telemedicine visit? Some patients are rapid adopters of technology; others are more reluctant. Will the patients be willing to be seen via telemedicine? In our telemedicine practice, we initially assumed, as did many others, that younger patients would be more amenable to telemedicine visits. ${ }^{1}$ We were surprised that our patient population had a bimodal distribution. We had many younger patients but also had a significant number of older patients who were of retirement age. It is important to recognize that this group of patients grew up with a television in the home. They are pleased with their electronic tablets. They are comfortable engaging in a telemedicine encounter. ${ }^{2}$ In our experience, they were very satisfied with a telemedicine clinic offering. As the investigators of this study ${ }^{2}$ noted, telemedicine brings medicine back to the narrative description of the presenting complaint (History of Present IIIness) and the clinician's observational skills. The ability to communicate with a patient is an essential skill necessary for a successful telemedicine encounter. Providers need to show that they are listening to their patients to help earn their trust. This study concluded that telemedicine was more reminiscent of traditional doctor-patient interactions that relied more on communication and trust rather than primarily depending on test results.

\section{WHAT ARE THE DIFFERENT TELEMEDICINE MODELS?}

Synchronous telemedicine can be performed in several ways. The 2 major models are center-tocenter (C2C) and center-to-home $(\mathrm{C} 2 \mathrm{H})$.

$\mathrm{C} 2 \mathrm{C}$ requires the patient to be seen in an approved clinical location. ${ }^{3}$ This location may be the primary care physician's office, the dental office, ${ }^{4}$ or in some states the school. ${ }^{5}$ There are trained personnel who will greet the patient, set up the telemedicine visit for the patient, and take vital signs and appropriate clinical history. This process is similar to an in-person visit and current previsit duties performed by the nurse or medical assistant. There is someone available if there are any issues that arise during the visit. The health care practitioner conducting the telemedicine visit is physically in the practitioner's own clinic. The patient is physically at a health care facility (originating site) that is closer to the patient's home. This arrangement reduces travel time for the patient. This type of visit is recognized by many insurance payors and most states have parity for these visits, ${ }^{3}$ which means that the reimbursement for a telemedicine visit must be the same as for an inperson visit as mandated by state legislation, although there are nuances in this legislation and variances between states.

$\mathrm{C} 2 \mathrm{H}$ allows the patient to be seen in a nonclinical setting, such as the home or place of work. There are no trained personnel with the patient and the patient navigates through the telemedicine

\section{Table 3}

Cost analysis worksheet final tally

\begin{tabular}{llll} 
& C2H Telemedicine & C2C Telemedicine & Satellite Clinic \\
\hline Total revenue & + & + & + \\
\hline Total single costs & - & - & - \\
\hline Total monthly costs & - & - & - \\
\hline Net gain/loss & - & - & - \\
\hline
\end{tabular}

Courtesy of Barry Fields. Atlanta, GA. 
visit alone. Many telemedicine platforms offer immediate assistance in case of technical issues and the platforms are usually straightforward and uncomplicated. These visits have historically not been covered by insurance payors; however, with the national emergency created by COVID19 , these visits are now being reimbursed by most payors. With the 1135 waiver, $\mathrm{C} 2 \mathrm{H}$ telemedicine has suddenly become mainstream. At the time of this writing, readily available audiovideo platforms such as Skype and FaceTime are able to be used. It is unclear whether reimbursement will continue after the coronavirus emergency. It is also unclear whether these platforms will continue to be accepted. Realistically, an HIPAAcompliant model will need to emerge.

The $\mathrm{C} 2 \mathrm{H}$ model has been gaining popularity among the direct-to-consumer models for several years. These models are typically hosted by a telemedicine platform company. Patients pay for this directly. Fees are paid to the health care practitioner with part of the fee going to the telemedicine company. Sometimes these fees are submitted to insurance companies by the patient or they are taken out of a health-savings account. Data show that patients are willing to pay for this convenience. .,7 $^{6}$

There has also been a shift toward e-visits in health care systems as well as with certain insurance carriers. ${ }^{8}$ These e-visits are hosted on the insurance company's Web site or on the Web site for a hospital system. Insurance coverage for these visits is variable and often depends on the specific plan. ${ }^{9}$ Health care systems seem to be moving toward interchangeable in-person and telemedicine visits with consistent providers, ${ }^{10}$ and this has long been a criticism of telemedicine. There have been a few companies who have offered virtual visits with mostly out-of-state physicians using a direct-to-consumer model, which did not always allow for longitudinal care and often directly opposed primary care models, although not universally. Data show that patients prefer to be seen by their own providers via telemedicine than a new provider via telemedicine, even if that new provider is within the same health system. ${ }^{11}$ By larger health systems offering electronic visits with their own providers, patients benefit from a shared electronic health record as well as continuity of care. They are able to schedule a visit online, upload relevant information or paperwork, and engage in a telemedicine visit with their own health team from their home or place of work. These visits are now routinely performed during the COVID-19 pandemic and costs have either been waived or covered under payor policies. Some differences in these two models are outlined in Fig. 2.

There are also 2 models of scheduling patients. If staff are traveling to the patient location (originating site) and using dedicated equipment (such as a telemedicine robot or telemedicine cart that is the property of the practice), it may be prudent to devote the entire day to that particular site. This approach allows higher efficiency because staff are traveling to set up the equipment and serve as the telepresenter.

If staff are shared with the originating site, it is then feasible to place those patients into existing clinic slots (any day) that are more convenient for the patients. It is then possible to quickly switch from in-person visits to virtual visits, which is particularly helpful if the telemedicine platform being used is Web based with plug-and-play equipment such as the camera, e-stethoscope, speakers, and microphone that remain at the originating site. This model is often used when starting out with a telemedicine practice because the financial outlay is significantly lower. This model can also be used for the direct-to-consumer $\mathrm{C} 2 \mathrm{H}$ telemedicine model (minus the e-stethoscope), although some clinicians prefer to have a dedicated day for these patients as well. By incorporating virtual visits with in-person visits, any patient no-show can potentially be filled by a virtual last-minute visit. $^{12}$ Many telemedicine

\begin{tabular}{|c|c|c|}
\hline Telemedicine Model & Center to Home (C2H) & Center to Center (C2C) \\
\hline Advantages & $\begin{array}{l}\text { - Implementation costs lower } \\
\text { - } \quad \text { Ease of patient access } \\
\text { technology }\end{array}$ & $\begin{array}{l}\text { - More similar to live office visit } \\
\text { - Utilization of personnel and } \\
\text { diagnostic tools } \\
\text { - Reliable and higher-quality } \\
\text { technology } \\
\end{array}$ \\
\hline Disadvantages & $\begin{array}{l}\text { - } \quad \text { Privacy more difficult to control } \\
\text { - No tools or personnel available } \\
\text { - } \quad \text { Variable signal quality/reliability }\end{array}$ & $\begin{array}{l}\text { - Remote site agreement required } \\
\text { - Higher equipment and personnel } \\
\text { costs } \\
\text { - Less convenient to patients }\end{array}$ \\
\hline
\end{tabular}

Fig. 2. Comparison of $\mathrm{C} 2 \mathrm{H}$ versus $\mathrm{C} 2 \mathrm{C}$ models. (Courtesy of Dr. Jaspal Singh, Charlotte, NC.) 
platforms allow providers to toggle their availability in real time so patients can connect immediately.

\section{TECHNICAL CONSIDERATIONS}

The most basic requirements for a telemedicine visit are a video camera, a microphone, and a high-speed Internet connection. The telemedicine platform must provide a secure connection. The technology has improved so rapidly that the minimum standards can be satisfied with a typical smartphone or tablet device, ${ }^{13}$ although authentication may be required ${ }^{14}$ for security. There are no current HIPAA requirements for smartphone authentication, but this is likely to be updated. ${ }^{15}$

One important consideration is the telemedicine platform itself, which must be a secure, HIPAAcompliant private connection. Recently, these requirements have been loosened under the 1135 national emergency waiver but will likely revert back to requiring a HIPAA-compliant system. The specific platform largely depends on the clinician's preference. There are companies that offer monthly subscriptions and supply all of the necessary training. Some interface with the existing electronic medical record (EMR). The features offered vary. Some include the ability to take notes and generate a PDF of the visit that can be directly uploaded into the EMR. Some include the ability to take credit card information from the patient before the visit and provide billing services. Some submit billing to insurance for reimbursement. The levels of service are variable and are apparent in the cost structure.

If the clinical visit will require more than the minimal technology, there are varying levels of sophistication available for telemedicine. There is a telemedicine robot $^{16}$ that can be manipulated remotely to maneuver through clinic hallways. This robot has a video camera, microphone, and screen. Often there are drawers that can be opened in order to use examination extenders, such as an electronic stethoscope or oral camera. These can be placed into position by the telepresenter or by the patient with the clinician's guidance. The sounds are transmitted through the software and audio system. There is often the ability to record these sounds and place them into the health record, although there is little reason to do so. Because this is not routinely done with an inperson visit, there is no compelling reason to do this for a telemedicine visit. The purpose of the telemedicine visit is to mirror the in-person visit. If it is something that would not be routinely done in person, there is likely no reason to do it during a telemedicine visit.
Examination extenders are also available without a telemedicine robot. They are add-on pieces of equipment that either plug into the computer (usually via USB port) or are stand-alone devices with internal power and memory. There are oral cameras ${ }^{17}$ that send the image via the video connection directly. These images can be shared with the patient or seen by the provider alone. These images can be saved into the electronic health record if so desired (ie, preoperative evaluation for adenotonsillectomy or to share images with a consultant; eg, a dentist for oral appliance therapy [OAT]). These more robust technologies carry a higher price tag but, depending on the practice, many prove to be invaluable. Choosing hardware and software that interface with the current system may be wise. Communicate with the IT staff, as well as the administrators and fellow clinicians, to determine the most realistic setup for the practice.

It is often helpful to create a telemedicine troubleshooting contact list. This list is a quick reference containing contact information for IT support, the originating site (where the patient is), the Internet provider, and (most importantly) the telepresenter's contact information. It is vital to be able to reach the telepresenter throughout the patient visit in case there are technical issues or if there are clinical issues requiring immediate intervention. The information should also be readily available for the telepresenter, and a similar troubleshooting contact list should be available at the originating site. These lists are often physically placed beside the computer monitor for easy access or are adhered to the monitor itself. They should be updated on a regular basis as part of the telemedicine policy guidelines. A sample troubleshooting contact list is provided in Fig. 3 .

\section{WHAT ARE THE LEGAL IMPLICATIONS?}

This brief article is not meant to be a comprehensive legal review. Clinicians should consult their attorneys because this article is not intended to be legal advice.

According to the American Telemedicine Association, ${ }^{18}$ a synchronous telemedicine visit is perfectly legal as long as clinicians abide by official guidelines. These guidelines vary from state to state. Some important considerations before implementing a telemedicine practice revolve around these issues:

1. Can a doctor-patient relationship be established via telemedicine?

2. Can medications be prescribed for patients seen via telemedicine? 


\section{Troubleshooting Contact List}

As you are setting up your telemedicine program, make sure to fill out the troubleshooting contact list, so you are prepared in case issues arise.

Local Coordinator:

Contact Name:

Telephone Number: (ext):

Email:

Remote Site Coordinator:

Contact Name:

Telephone Number: (ext):

Email:

Telepresenter:

Contact Name:

Telephone Number:

Email: (ext):

Hardware Issues

General Information Technology Help Desk: (Local Computer Issues) Contact Name:

Telephone Number: (ext):

Email:

Computer make, model, serial number:

Internet Service Provider: (Networking Issues)

Contact Name:

Telephone Number:

Email (ext):

Fig. 3. Sample telemedicine troubleshooting contact list. (From AASM Sleep Technology Implementation Guide, American Academy of Sleep Medicine Telemedicine Implementation Task Force, 2016, Jaspal Singh, MD Chair; M. Safwan Badr, MD; Lawrence Epstein, MD; Barry Fields, MD; Dennis Hwang, MD; Seema Khosla, MD; Kimberly Mims, MD; Brandon Peters, MD; Afifa Shamim-Uzzaman, MD; Emerson Wickwire; with permission.)

3. Can testing be ordered for patients seen via telemedicine?

4. Can DME treatment be prescribed for patients seen via telemedicine, including positive airway pressure (PAP), OAT, and nasal expiratory PAP devices?

The answers to these specific questions depend on the state. Telemedicine is patient-centric. The rules apply to the state where the patient is, but health care practitioners must also be in compliance with their home state regulations regarding the practice of telemedicine. This requirement is a little simpler for practices where the provider and the patient are in the same state, which is often a good place to begin. The Interstate Medical Licensure Compact ${ }^{19}$ has continued to grow and helps to streamline the application process if multiple state licenses are desired. It is not a national license but aims to remove barriers and share information to facilitate licensure in multiple states.

There are also nuances to these legal questions. For example, in states where a doctor-patient relationship cannot be established via telemedicine, clinicians are often able to provide telemedicine services to the established patients. It is common, in these circumstances, for the initial visit to take place in person with all of the followup done via telemedicine. This situation is also an excellent opportunity to query the patients on their willingness to engage in follow-up telemedicine visits. This would satisfy Centers for Medicare \& Medicaid Services (CMS) regulations ${ }^{20}$ regarding the physical examination, which must be documented in order to script PAP therapy (body mass index, neck circumference, focused cardiopulmonary and upper airway system evaluation). ${ }^{21}$

\section{WILL THE CLINICIAN GET PAID FOR A TELEMEDICINE VISIT?}

No matter how altruistic the clinicians' intentions, a telemedicine practice cannot survive if telemedicine visits are not reimbursed. Billing for a telemedicine visit is straightforward but must be done 
correctly. The visit is billed with a typical Evaluation and Management (E\&M) code for professional services along with a telemedicine modifier code. ${ }^{22}$ The telemedicine modifier is GT Q3014. GT indicates that the synchronous telemedicine occurred via interactive audio and video. The video component must be present. CMS (Centers for Medicare and Medicaid Services) asks for a 95 modifier to be used instead. There is a GQ code, which indicates that the service was asynchronous. As of January 2020, there were only 16 states that did not recognize synchronous telemedicine visits. ${ }^{23}$ It is also important to note that, during the 1135 COVID-19 waiver, these modifiers are changing rapidly with significant differences between payors. It is vital to check with local payors to ensure appropriate payment for services.

Telemedicine visits between a clinician and a patient must mirror the in-person visit. The billing also mirrors billing for an in-person visit. Billing can be done for time or via a traditional E\&M code plus a GT modifier. It is important to recognize that this is not a reduced fee modifier. Synchronous telemedicine visits are reimbursed at the same rate as the in-person visit in most states ${ }^{24}$ where parity legislation has been passed. There is also a facility fee that can be charged in addition to the E\&M code. Although this facility fee is not always reimbursed, when it is, it also allows the clinician to recoup expenses for telemedicine equipment and/or room rental at the originating site. Billing is the critical component of a telemedicine practice; if this part is not executed correctly, the practice will not survive. Billing and reimbursement are discussed elsewhere in this issue.

\section{HOW TO PERFORM A TELEMEDICINE VISIT}

The emphasis thus far has been to show that telemedicine is not a new way of practicing medicine, it is simply a tool that allows the practice of medicine remotely. The patient visit is the same, with few exceptions. The history taking is the same, and the laboratory review and decision-making processes are the same. However, the differences are important to recognize. It is vital to take the time to create an appropriate clinical experience for both the patient and the clinician, which involves setting up the environment and paying attention to specific details that will allow the clinician to execute a successful telemedicine encounter. These details are outlined in Fig. 4.

1. Be mindful of the clinical environment. This requirement pertains mostly to the $\mathrm{C} 2 \mathrm{C}$ model, where the patient's surroundings can be controlled. Although this is also important in the $\mathrm{C} 2 \mathrm{H}$ model, the clinician has less control over the patient's space. Before the $\mathrm{C} 2 \mathrm{H}$ visit, educational, assistive materials should be provided to the patient to ensure a private, quiet room with good lighting and minimal disruptions. The same requirement applies to the C2C visit. It should be treated the same as an in-person visit. The telepresenter should ensure that the door is closed and that there are no distractions (eg, loud noises, frequent disruptions, conversations in the hallway) during the visit. Privacy should be ensured and patients treated in a professional manner.

2. Pay attention to the details. The space should be well lit for both the patient and the clinician. It is helpful to do a trial run before the visit to ensure that the audio and video are of good quality ahead of time.

3. Be mindful of the equipment. The audiovisual equipment should be positioned unobtrusively. The microphone should be placed in close proximity to the patient. The speakers should be adjusted to a comfortable level. The patient should be able to quickly forget about the equipment as the visit continues.

4. Pay attention to the eyeline. Maintaining eye contact is an important part of any clinic visit. Patients often think that clinicians are not paying attention if they are not maintaining eye contact throughout the visit. ${ }^{25}$ This requirement is much easier to do in person than via a virtual visit. It is therefore important for clinicians to be mindful of where their eyes appear to be looking. It is helpful at the beginning of the visit for clinicians to assure their patients that they are looking at them on the monitor but that they may have to avert their eyes in order to take notes. It is worthwhile to have the telepresenter sit in the patient's seat before the visit to provide feedback about the eye position. Pay attention to both the horizontal and the vertical eyelines. Once the telepresenter has confirmed where the eyes should be, place a marker on the screen to serve as a reminder of where to look. If picture in picture is available on the platform, it is helpful to move the thumbnail view into that location so as to be able to quickly look the patient in the eye while also making sure that the expression is appropriate and conveys engagement in the visit.

5. Minimize the e-mail and turn off phone notifications. This session is a patient interaction that mirrors the in-person interaction. Clinicians do not check e-mails during visits 


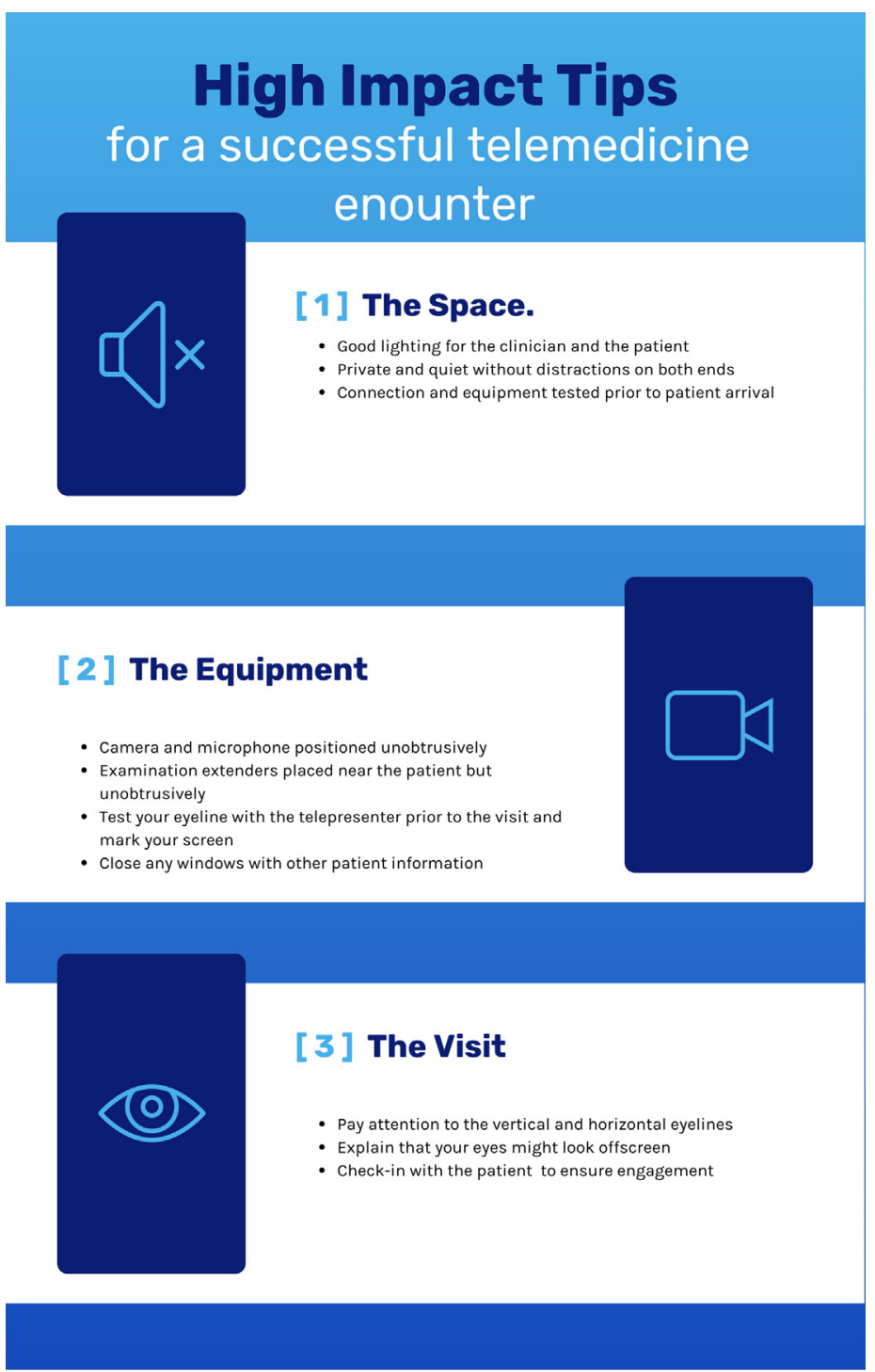

Fig. 4. High-impact tips for a successful telemedicine encounter.

when a patient is in the office and they should not check them during an e-visit.

6. Prepare ahead of time. Test the connection. Check the lighting and the sound. Make sure the telemedicine platform is functioning appropriately, including the screen-share feature.

7. Ensure that no other patient information is on the computer if the intention is to share the screen; this is another reason why e-mails should be turned off or minimized with notifications turned off.

8. Clinicians can choose which of the monitors to share. It is often helpful to move the specific information related to the patient to the external monitor and then share that screen with the patient. This ability allows clinicians to then have the EMR pulled up on the primary monitor. They can then move the selected documents that they wish to share.

9. Clinicians may wish to have the patient upload information before the visit, such as sleep logs or sleep tracker information. They can also complete the regular paperwork ahead of time and upload this information for the review.

10. Above all, remember that a telemedicine visit is a regular patient visit that is done remotely. Relax. Once the clinician has practiced and worked out the details, it should flow the same way as the regular in-person clinic visits. 


\section{HOW WILL TELEMEDICINE CONTINUE TO CHANGE THE PRACTICE? WHAT DOES THE FUTURE OF TELEMEDICINE LOOK LIKE?}

Clinical algorithms respond to evolving technology. What used to require fully attended polysomnography can now be accomplished in the patient's home faster and in a more costeffective manner. ${ }^{26}$ Clinicians are able to reach patients who would otherwise never be seen by using telemedicine technology. ${ }^{27}$ This, in turn, helps to keep communities healthier and keep health care dollars within those communities. The practice of sleep medicine continues to change with an arc toward patient-centricity. Patients are becoming health care consumers. Health care has evolved from a paternalistic approach to one of shared decision making. Patients expect more convenience $^{28}$ and this often results in more ondemand knowledge (patients can access their electronic health records), faster communication (they can communicate directly with their health care practitioners via secure messaging), and access to new information (via the Internet). Many of these health care consumers also expect to be able to have a face-to-face visit with their clinicians on demand in the convenience of their homes or places of work. Telemedicine has become an expectation. ${ }^{29}$ Studies have also shown that patients are willing to pay for this convenience. , 30,31 Many companies have embraced a direct-to-consumer approach, as described earlier in relation to telemedicine models.

Health care systems have also seen the cost savings of telemedicine. ${ }^{32,33}$ They have also been able to apply this technology to population health management. Large systems are able to mine their data and identify patients who are at a high risk of sleep apnea. They are then able to deploy questionnaires and engage with those patients. Those patients are then evaluated by a clinician, either via questionnaire or an e-visit. Testing is ordered and the results are reviewed by the overseeing physician. Treatment can be ordered and follow-up is also done via telemedicine. By managing large populations, health care systems can improve the overall health of their covered entities. This ability results in a reduction in health care spending, which can then benefit the system as a whole. ${ }^{34}$ Artificial intelligence (Al)-assisted algorithms can be applied to the electronic health record to further evaluate which patients may be appropriate for further evaluation and testing/ treatment. ${ }^{35}$ As the electronic health record and Al both improve, this may become standard for large health systems or those who are selfinsured. Insurance companies may also apply Al- assisted algorithms to their covered entities in an attempt to reduce overall health care spending by identifying patients at high risk.

Much more patient-initiated testing is now being done. The ubiquity of consumer sleep technology, such as fitness trackers, has increased the awareness of the importance of sleep. It has also drawn attention to the prevalence of underlying sleep disorders. Consumers who find abnormalities in their sleep, as determined by their sleep technology, are often encouraged to seek further evaluation. They may seek the counsel of their primary care physicians or sleep physicians. They are also looking online for answers to their questions. This technology may be a useful tool to engage patients ${ }^{36}$ and may allow patients to be more aware of their sleep. Patients who use consumer sleep technology may have an affinity for technology and, as such, may be more willing to pursue a telemedicine interaction. Some consumer sleep technology companies have described a future in which consumers will be alerted to a possible sleep disorder via their wearable trackers, and will be able to launch a telemedicine visit via an app on their phones. ${ }^{37}$

This vision may be closer to reality now. There are several tele-sleep clinics that currently operate using the direct-to-consumer model. They charge a fee for consultation and testing, and then are able, if they deem it to be appropriate, to provide a prescription for a medication or device. These fees can often be reimbursed by the patient's health insurance. This system allows tele-sleep clinicians to work with lower operating expenses while still providing appropriate care to their patients. Tele-sleep clinicians may be clinicians who only see patients via telemedicine or they may be clinicians who also see patients in person. Longitudinal relationships can be maintained via telemedicine, although typically in the direct-toconsumer model the patients are evaluated, treated, and then sent back to their primary care physicians. If issues arise, they can reconsult the tele-sleep clinician but usually these relationships are episodic. For patients with straightforward obstructive sleep apnea (OSA) who do well on PAP therapy, this model works well.

Implementing a telemedicine program may seem daunting. It is important to recognize that telemedicine is simply another method of delivering medical care. It is not a new way to practice medicine; clinicians are able to practice medicine as they currently do, but it allows them to connect with their patients using technology. This technology allows clinicians to expand their current reach and, more importantly, allows them to reach patients who may not have ever been seen because of geographic or travel limitations. ${ }^{38}$ Technology helps clinicians to 
deliver care into areas that are underserved. By providing health care to these populations, the overall health of the communities improves. ${ }^{38}$

Sleep medicine suffers from a lack of urgency. When people have chest pain, they recognize that they need to go to the emergency room (ER) to be seen. There are public service announcements teaching about the signs and symptoms of a stroke so people can identify it sooner and seek treatment more quickly. Very few people go to the ER to be evaluated for snoring. The current model of OSA diagnosis leaves $80 \%$ of patients undiagnosed. ${ }^{39}$ This system is extremely fragmented with numerous bottlenecks along the algorithm. One common barrier is the need to travel to be seen by a sleep specialist, particularly in rural communities. This situation creates yet another barrier to care. Untreated sleep disorders carry with them significant morbidity. ${ }^{40}$ Clearly, the current paradigm is far from ideal. Telemedicine is one way to reduce barriers for patients. By eliminating the need for them to travel great distances, they are more likely to undergo testing and treatment of their underlying sleep disorders. Consumer sleep technology may be another way to identify those at higher risk of a sleep disorder. Those consumers may then pursue further evaluation and treatment. Al algorithms applied to large populations may identify more patients at high risk of a sleep disorder. Perhaps all of these modalities will help clinicians to improve their ability to identify and treat the immense number of patients who have an undiagnosed and therefore untreated sleep disorder.

Telemedicine is just another tool in the toolkit. It is up to clinicians to decide how they want to use this technology to reach their patients before nonclinicians make those decisions instead. Embracing this technology, which has been around for decades, may allow the gaps in the current health care algorithm at last to be bridged. The COVID19 pandemic has been an ignition event for telemedicine. Now is the time to embrace this technology and build a sustainable telemedicine program.

\section{DISCLOSURE}

The author has nothing to disclose.

\section{REFERENCES}

1. Available at: https://www. beckershospitalreview.com/ healthcare-information-technology/82-of-young-adultswould-prefer-telehealth-to-in-person-visit.html Accessed January 19, 2020.

2. Available at: https://www.ncbi.nlm.nih.gov/pmc/ articles/PMC5752645/ Accessed January 19, 2020.
3. Center for connected health policy. Available at: https://www.cchpca.org. Accessed January 19, 2020.

4. Available at: https://mhealthintelligence.com/news/ dentists-use-telehealth-to-improve-access-to-careand-fight-a-phobia Accessed January 19, 2020.

5. Available at: https://www.amdtelemedicine.com/ telemedicine-resources/documents/ATAstate-medicaidbest-practice — school-based-telehealth.pdf Accessed January 19, 2020.

6. Available at: https://patientengagementhit.com/news/ 77-of-patients-want-access-to-virtual-care-telehealth Accessed January 19, 2020.

7. Available at: https://www.idigitalhealth.com/news/ patients-clinicians-satisfied-with-telehealth-for-followupcare Accessed January 19, 2020.

8. Available at: https://www.bcbsmonlinevisits.com/ landing.htm Accessed January 19, 2020.

9. Available at: https://www.bcbs.com/the-health-ofamerica/articles/telehealth-quality-care-your-fingertips Accessed January 19, 2020.

10. Available at: https://unw.advisory.com/research/caretransformation-center/care-transformation-center-blog/2018/ 10/behavioral-health-access Accessed January 19, 2020.

11. Available at: https://www.ncbi.nlm.nih.gov/pmc/ articles/PMC5704580/ Accessed January 19, 2020.

12. Available at: https://blog.evisit.com/telemedicine-solvescostly-problem-no-shows Accessed January 19, 2020.

13. Gough F, Budhrani S, Cohn E, et al. Practice guidelines for live, on demand primary and urgent care. Telemed J E Health 2015;21:233-41.

14. Available at: https://www.ncbi.nlm.nih.gov/pmc/ articles/PMC5716614/ Accessed January 19, 2020.

15. Luxton DD, Kayl R, Mishkind MC. mHealth data security: the need for HIPAA-compliant standardization. Telemed J E Health 2012;18:284-8. https:// doi.org/10.1089/tmj.2011.0180. Available at:.

16. Available at: https://www.businesswire.com/news/ home/20130506005495/en/InTouch-Health-iRobot-An nounce-Customers-Install-RP-VITATM Accessed January 19, 2020.

17. Available at: https://fireflyglobal.com/de605-generalexamination-camera/. Accessed January 19, 2020.

18. Available at: https://www.cchpca.org/telehealthpolicy/current-state-laws-and-reimbursement-policies Accessed January 19, 2020.

19. Available at: https://imlcc.org/ Accessed January 19, 2020

20. Available at: https://unw.genesishealth.com/caretreatment/neuroscience/sleep/patient-resources/medicareguidelines-for-cpap/ Accessed January 19, 2020.

21. Available at: https://www.usa.philips.com/c-dam/ b2bhc/master/whitepapers/sleep-therapy-compliance/ 1084892_PhysDocumentforPAP_HelpHint.pdf Accessed January 19, 2020.

22. Available at: https://liveclinic.com/blog/gt-modifiertelemedicine-billing Accessed January 19, 2020 


\section{Khosla}

23. Available at: https://www.americantelemed.org/ initiatives/2019-state-of-the-states-report-coverageand-reimbursement/ Accessed January 19, 2020.

24. Available at: https://www.americantelemed.org/ policy/state-activity/ Accessed January 19, 2020.

25. Available at: https://www.physicianspractice. com/pearls/patients-three-biggest-complaintsabout-your-practice Accessed January 19, 2020.

26. He K, Kim R, Kapur VK. Home- vs. Laboratorybased management of OSA: an economic review. Curr Sleep Med Rep 2016;2:107-13.

27. Available at: https://www.cdc.gov/chronicdisease/ resources/publications/factsheets/telehealth-inrural-communities.htm Accessed January 19, 2020.

28. Available at: https://www.ortholive.com/blog/but-dopatients-want-telehealth-the-survey-says-yes Accessed January 19, 2020.

29. Available at: https://patientengagementhit.com/ news/retail-consumer-experience-key-in-consumerdriven-healthcare Accessed January 19, 2020.

30. Available at: https://www.ncbi.nlm.nih.gov/pubmed/ 15603629 Accessed January 19, 2020.

31. Available at: https://www.prnewswire.com/newsreleases/virtual-visits-with-medical-specialists-drawstrong-consumer-demand-survey-shows-300475757. html Accessed January 19, 2020.
32. Available at: https://www.urac.org/blog/telehealthoffers-cost-savings-opportunities-hospitals-andpatients Accessed January 19, 2020.

33. Available at: https://www.healthcarefinancenews. $\mathrm{com} /$ news/telehealth-eliminates-time-anddistance-save-money Accessed January 19, 2020.

34. Available at: https://mhealthintelligence.com/news/ healthcare-wakes-up-to-the-value-of-mhealth-andsleep Accessed January 19, 2020.

35. Available at: https://link.springer.com/article/10. 1007/s41649-019-00096-0.

36. Khosla S, Deak MC, Gault D, et al. Consumer sleep technology: an American Academy of Sleep Medicine position statement. J Clin Sleep Med 2018; 14(5):877-80.

37. Connor Heneghan, PhD, speaker at the AASM Sleep Disruptors Conference, Chicago, March 2019.

38. Available at: https://www.cdc.gov/chronicdisease/ pdf/factsheets/Rural-Health-Telehealth-H.pdf Accessed January 19, 2020.

39. Available at: https://aasm.org/resources/pdf/sleepapnea-economic-crisis.pdf Accessed January 19, 2020.

40. Available at: https://www.sleephealth.org/sleephealth/the-state-of-sleephealth-in-america/ Accessed January 19, 2020. 